\title{
Symptomatic uterine fibroids in pregnancy - wait or operate? Own experience
}

\author{
Anna Fuchs ${ }^{1}$, Agnieszka Dulska ${ }^{1}$, Jerzy Sikora ${ }^{1}$, Iwona Czech ${ }^{1}$, \\ Violetta Skrzypulec-Plinta ${ }^{2}$, Agnieszka Drosdzol-Cop ${ }^{1}$ \\ ${ }^{1}$ Department of Pregnancy Pathology, Department of Woman's Health, School of Health Sciences in Katowice, \\ Medical University of Silesia, Katowice, Poland \\ ${ }^{2}$ Department of Woman's Health, School of Health Sciences in Katowice, Medical University of Silesia, Katowice, Poland
}

\begin{abstract}
Objectives: Uterine fibroids are one of the most common benign tumors of the female genital tract. The major complication of myomas in pregnancy is a recurrent pain, however the misscariage is the main threat. The negative impact of myomas on the course of pregnancy may also result in i.e. uterine bleeding, higher incidence of a maternal-fetal incommunicability, an incorrect position of the fetus and its deformities.

Material and methods: The patient aged 31 was admitted to Mother and Child Health Center in Zabrze due to the threatened miscarriage. The primigravid at 19 weeks' gestation was previously diagnosed with myoma. On admission the ultrasonography revealed one alive fetus in the uterus and a nodular change on the right side of the uterine fundus, $13 \times 11 \mathrm{~cm}$ in size and non-homogenous echo.

Results: The patient was qualified to the conservative myomectomy. 11 days after the enucleation of $25 \mathrm{~cm}$ in diameter myoma, patient in good condition, with the maintained, alive foetus was discharged from the hospital. Patient at 34 weeks gestation was re-admitted due to the beginning of uterine contraction. After one week of observation within the ward, with tocolytic drugs and steroids administered, at 35th week of pregnancy the patient gave birth to a live daughter via the Ceasarian section.

Conclusions: Prenatal myomectomy can be safely performed in the first and second trimester of pregnancy, however it is recommended to deliver the baby via Caesarean section, due to fear of intrauterine rupture of the uterus.
\end{abstract}

Key words: uterine fibroids; prenatal myomectomy; pregnancy complications

Ginekologia Polska 2019; 90, 6: 320-324

\section{INTRODUCTION}

Uterine fibroids are benign tumors, of unknown aetiology, arising from uterine smooth muscle cells. They are one of the most common benign tumors of the female genital tract, occurring in $20-50 \%$ of women in reproductive age [1]. The prevalence of uterine fibroids during pregnancy is underestimated. Due to late procreation, the prevalence of uterine fibroids in over 35-years-old women treated for infertility ranges from $12 \%$ to $25 \%$ [2].

The correlation of uterine fibroids with unfavorable perinatological results was unequivocally determined. The prospective studies, using ultrasound to monitor uterine fibroids during pregnancy, showed that the majority of myomas (60-78\%) did not undergo any changes during pregnancy [3], however about $1 / 3$ of them may expand in the first trimester of pregnancy [2].
The negative impact of myomas on the course of pregnancy and on perinatological results has not been clearly defined. The main threat posed by the presence of myomas in early pregnancy is miscarriage. The incidence of spontaneous abortion is almost doubled taking pregnant women with uterine fibroids into consideration. The size of a single myoma does not affect the incidence of miscarriages, but numerous myomas may even triple the incidence of early pregnancy losses (23.6\% and $8.0 \%$ respectively) [2].

Early miscarriage is more common among women with fibroids located in the uterine body compared to the lower part of the womb and in the case of intramural or submucosal myomas. It has been noticed that the presence of fibroids increases the uterine contractile activity. They may also cause a compression effect on the developing fetal 
egg. The myomas are also responsible for disturbances in the blood supply to the placenta and fetus, as well as for the increased risk of uterine bleeding in early pregnancy [4].

The location of the fibroid determines the risk of bleeding. Bleeding in early pregnancy is much more common in cases with sub mucous fibroids or insertion of the placenta near a fibroid and may have an adverse impact on fertility [5].

The situation becomes much more complicated in late pregnancy. According to literature data, the major complication is the syndrome of painful myomas of pregnancy. It occurs in second- and early third-trimester and is characterized by pain and occasionally bleeding.

Moreover, pregnant women with fibroids, in comparison to pregnant women without them, are more likely to have premature uterine contraction $(16.1 \%$ and $8.7 \%$ respectively) and premature delivery (16.0\% and $10.8 \%)$. This is particularly true for cases where the fibroids contact the placenta [2].

Furthermore, fibroids are associated with a threefold increase of the risk of placental abruption. Confirmed risk factors for placental abruption are as follow: submucosal myomas, placental implantation in direct contact with uterine myoma (58\%, compared to $2.5 \%$ in other sites) and myomas with volume greater than $200 \mathrm{~cm}^{3}$ [6].

Another important aspect is the correlation between the presence of uterine fibroids and the placenta praevia. So far, this phenomenon has been evaluated only in two studies, which showed that uterine fibroids may double the risk of placenta praevia. This risk is comparable in patients after previous operations on the uterine myometrium (caesarean section, myomectomy) [7].

In addition, the influence of uterine myomas on the occurrence of fetal anomalies has been proven. Although, they do not affect the growth of the fetus, their presence may be associated with a reduction of blood flow through the placenta and clinical IUGR exponents. Rarely, large myomas may deform the uterine cavity by causing compression, causing fetal deformities such as: dolichocephaly (due to lateral pressure on the skull of the fetus), torticollis (incorrect neck position in utero) and weakness of one of the limbs $[4,8]$.

It should also be remembered that the risk of abnormal fetal position in pregnant women with myomas increases and in relation to the group of women with unaltered uterus, it occurs in $13 \%$ and $4.5 \%$ of cases respectively. Large fibroids, numerous myomas, fibroids in the lower uterus and submucosal myomas are documented risk factors for abnormal fetal position. Moreover, the presence of uterine fibroids is associated with an almost fourfold increased risk of pregnancy completion by caesarean section (respectively in $48.8 \%$ and $13.3 \%$ ) compared to the control group, due to above mentioned factors [8].

\section{MATERIAL AND METHODS}

Patient aged 31 was admitted to Mother and Child Health Center in Zabrze on February 21, 2018 due to threatened miscarriage (ICD10: O20.0). The primigravid at 19 weeks' gestation was previously diagnosed with myoma. First day of last menstrual period: October 15, 2017. Due date: July 22, 2018. At admission ultrasonography was performed with following results: one alive fetus in the uterus, biparietal diameter (BPD) $3.8 \mathrm{~cm}$ (corresponding 17w3d), head circumference $(\mathrm{HC})$ $15 \mathrm{~cm}$ (corresponding 18w0d), abdominal circumference (AC) $12 \mathrm{~cm}$ (corresponding $17 \mathrm{w} 5 \mathrm{~d}$ ), femur length (FL) $2.5 \mathrm{~cm}$ (corresponding $17 w 4 d$ ), average ultrasound age (AUA) $17 w 4 d$, fetal weight $208 \mathrm{~g}$, anterior placenta with no abruption or hematoma. Correct amniotic fluid index (AFI) and fluid translucency, fetal heart rate (FHR) detected. In right site of uterine fundus, a nodular change, in size of $13 \times 11 \mathrm{~cm}$ and non-homogenous echo, was found (Fig. 1). The structure was assessed as myoma. No deviations in laboratory urine test were found. The following abnormalities in laboratory blood tests were found: hemoglobin (HGB) $-11.8 \mathrm{~g} / \mathrm{dL}$ (norm: $12.0-16.0 \mathrm{~g} / \mathrm{dL}$ ), C-reactive protein (CRP) $13.01 \mathrm{mg} / \mathrm{dL}$ (norm: $<5 \mathrm{mg} / \mathrm{dL}$ ), D-Dimer 2018, 1 ngFEU/mL (norm: $<500$ ngFEU/mL), fibrinogen 546 mg/dL (norm: 200-420 mg/dL).

\section{RESULTS}

On February 22, 2018, after the above-mentioned examinations, the patient was qualified and subjected to the conservative myomectomy. After receiving patient's consent, general anesthesia was conducted. After preparing the operating field, a midline incision of the abdomen (with navel omission) was performed. An enlarged, spherical uterus was revealed, with the dimensions corresponding to 18 weeks of gestation. In the right site of uterine fundus the myoma with a diameter of $25 \mathrm{~cm}$, reaching the rib arches was found, accompanied by two smaller myomas - with diameter of $1 \mathrm{~cm}$ and $4 \mathrm{~cm}$ (Fig. 2). Enucleation of uterine fibroids was performed, next the sutures were put on

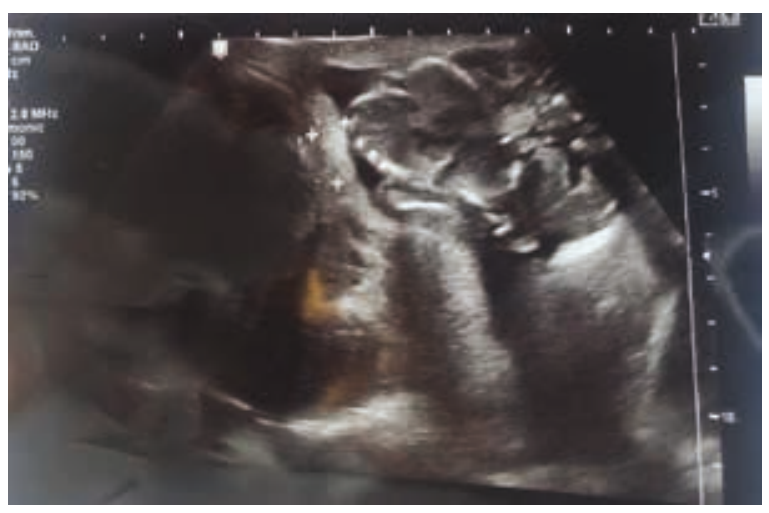

Figure 1. Patient's ultrasonography at hospital admission 


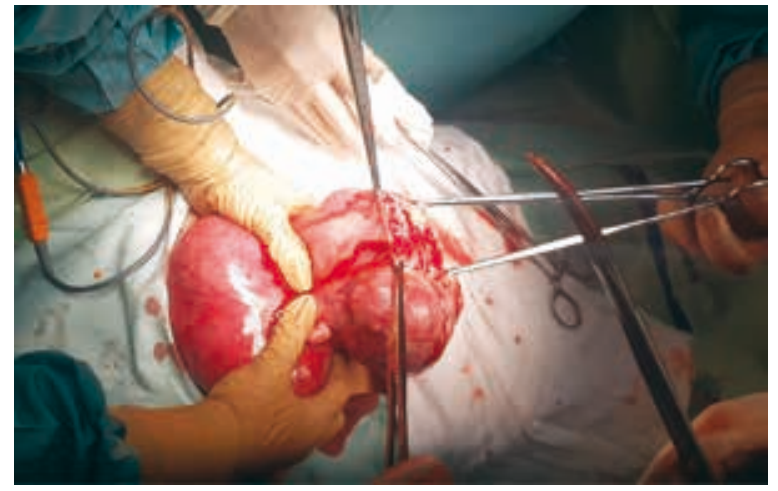

Figure 2. Gravid uterus compression by the $25 \mathrm{~cm}$ diameter leiomyoma

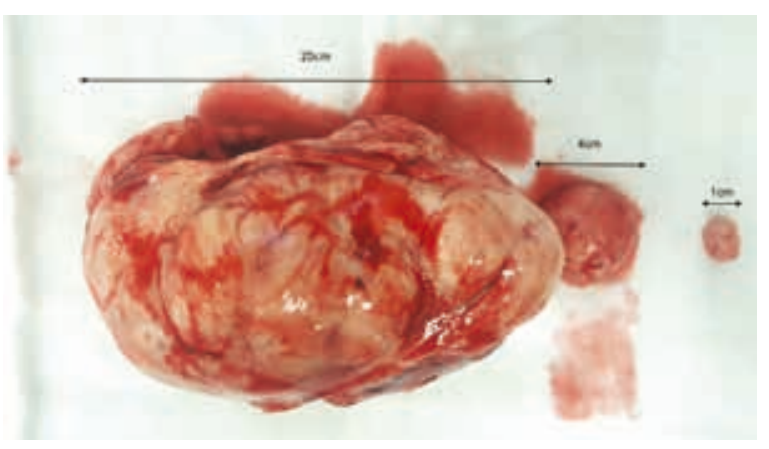

Figure 3. Resected myomas

the remaining cavities (Fig. 3). Four woundclot hemostatic gauzes were applicated on the remaining cavities. Next the hemostasis control was made. After the final inspection of the peritoneal cavity a drain was installed on the left side of the abdomen. Next the midline incision was closed. Patient in general good condition, with the maintained, alive foetus was transferred to the post-operative room.

The ultrasonography performed on February 23, 2018 raveled: one alive foetus in the uterus. FHR was detected and assessed as 157/min. Placenta detected in uterine fundus and on its anterior wall. Above the uterus, on the left side, hematoma with dimensions $93 \times 55 \times 21 \mathrm{~mm}$ was found. A control ultrasound was ordered for the next day.

On February 24, 2018 in the USG examination FHR was detected (FHR 144/min) as well as the foetus movements. Amniotic fluid pocket $-32 \mathrm{~mm}$. Kidneys on both side without obstruction. Intestinal loops widened No free fluids in the peritoneal cavity or in recto-uterine pouch.

The next control ultrasound examination, on the February 27, 2018 revealed one alive foetus in cephalic longitudinal lie with FHR 146/min. Anterior placenta with no abruption. Normal AFI. BPD $4.18 \mathrm{~cm}$ (corresponding: 18w4d), HC $15.12 \mathrm{~cm}$ (corresponding: 18w1d), AC $12.91 \mathrm{~cm}$ (corresponding 18w3d), FL $2.68 \mathrm{~cm}$ (corresponding: 18w1d). AUA 18 w2d and the fetal weight $234 \mathrm{~g}$. No features of car- diovascular centralization were found. Flow in the umbilical cord PI 1.4. The little amount of free fluid in recto-uterine pouch $(2.47 \times 3.23 \mathrm{~cm})$.

After the operation, the laboratory blood tests were performed daily. The hemoglobin level (HGB) decreased until the $3 \mathrm{rd}$ day after surgery, with the lowest value $7.8 \mathrm{~g} / \mathrm{dL}$ (norm: $12.0-16.0 \mathrm{~g} / \mathrm{dL}$ ), and then started to increase.

On the March 5, 2018, the last control USG was performed, with following results: one alive foetus in cephalic longitudinal lie with FHR 154/min. BPD $4.34 \mathrm{~cm}$ (corresponding: 19w0d), HC $16.28 \mathrm{~cm}$ (corresponding: 19w0d), AC $14.26 \mathrm{~cm}$ (corresponding: 19w4d), FL $3.29 \mathrm{~cm}$ (corresponding: 20w2d). AUA $19 w 3 d$ and the fetal weight $315 \mathrm{~g}$. Flow in the umbilical cord PI 1.17. Flow in fetal middle cerebral artery PI 1.44. After above results the decision of discharge from the hospital was made. Patient was discharged in general good condition, with following recommendations: Tardyferon (Ferrosi sulfas) $80 \mathrm{mg}$ p.o 3 times a day., Luteina (Progesterone) $100 \mathrm{mg}$ p.v. 2 times a day, Laktuloza (Lactulose) $7.5 \mathrm{~g} / 15 \mathrm{~mL}$ once a day. The post operation visit was scheduled after one week and during the examination patient did not report any pain or discomfort. The skin cuttings were healing correctly.

On the March 29, 2018 patient at 23 weeks' gestation was re-admitted to Mother and Child Health Center in Zabrze due to pain in lower abdomen. Pain was described as of the nature of renal colic. Laboratory blood tests taken at addmition revealed following deviations: elevated white blood

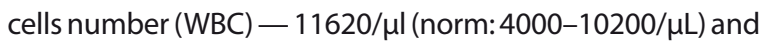
lowered erytrocates number $(\mathrm{RBC})-2.38 \mathrm{mln} / \mu \mathrm{L}$ (norm: 4.10-5.48 mln/ $\mu \mathrm{L}$ ), HGB $10.1 \mathrm{~g} / \mathrm{dL}$ (norm: $12.0-16.0 \mathrm{mg} / \mathrm{dL}$ ) and HTC 30.6 L\% (norm: 35.0-47.0 L\%). Urine specific gravity was also changed: 1.030 (norm: 1.015-1.025). Cervical swab for bacterial culture and sensitivity test was taken, and the empiric therapy with Amoxicilin/Clavulanic Acid (Taromentin) acid was administered.

Next the ultrasound was made with following results: one alive foetus, FHR detected. Anterior placenta with grade 1 maturity. Normal AFI. BPD $5.5 \mathrm{~cm}$ (corresponding: 22w5d), $\mathrm{HC} 20.2 \mathrm{~cm}$ (corresponding: 22w2d), AC $18.0 \mathrm{~cm}$ (corresponding $22 \mathrm{w} 5 \mathrm{~d}$ ), FL $4.3 \mathrm{~cm}$ (corresponding: 24w0d). The estimated fetal weight $577 \mathrm{~g}$. Kidneys on both side without obstruction.

The next day, on March 30, 2018 a surgical consultation took place. During the examination, the patient did not report any pain. The test result without deviations.

In the results bacterial culture of cervical swab, obtained after 5 days (on April 3,2018), Streptococcus agalactiae was not cultured.

After above described diagnostic the patient underwent psychiatric consultation. The patient confessed to the doctor that she had been feeling well until the time she was hospitalized. In the past, she attended psychotherapy due to anxiety disorders. At the time of the examination she tolerated her 
stay in the hospital badly, especially because of receiving contradictory information about her medical condition. the patient developed anxiety and sleep problems. Her husband's company made her feel better. The psychiatrist diagnosed the patient with adaptive disorders (ICD10: F43.2) and anxiety disorders in the anamnesis. The doctor recommended regular contact with a psychologist in the ward. In the event of deterioration in mental health, he recommended contacting a psychiatrist. Also in the case of clear need, he ordered Diphergan (Phrometazinum) 10mg temporarily.

During the stay in the hospital, the patient's health improved. The patient in a good general condition with recommendations for the use of magnesium, Tardyferon (Ferrosi sulfas), Luteina (Progesterone) and Lakcid (Lactobacillus rhamnosus), was discharged from the ward, on March 31,2018 with the pregnancy maintained alive.

On the June 20, 2018 patient was admitted to Mother and Child Health Center in Zabrze on due to the beginning of uterine contraction (ICD10: 060.0). The primigravid at 34 weeks' gestation underwent an ultrasonography test with following results: one alive foetus in the uterus, in the longitudinal fetal lie. Biparietal diameter (BPD) $8.5 \mathrm{~cm}$ (corresponding 34w2d), head circumference (HC) $29.8 \mathrm{~cm}$ (corresponding $32 \mathrm{w} 6 \mathrm{~d}$ ), abdominal cimcurference (AC) $30.2 \mathrm{~cm}$ (corresponding 34w1d), femur length (FL) $6.55 \mathrm{~cm}$ (corresponding $33 \mathrm{w} 5 \mathrm{~d}$ ), average ultrasound age (AUA) $3 w 4 d$, fetal weight $+/-2300 \mathrm{~g}$, anterior placenta with no abruption or haematoma. Correct amniotic fluid index (AFI) and fluid translucency, fetal heart rate (FHR) detected. Preserved continuity of the anterior wall of uterine muscle. Flow in the umbilical cord PI -0.56. Flow in fetal middle cerebral artery PI-1.1.

It was decided to observe the patient within the ward and terminate pregnancy at week 35 via caesarian section. Tocolytic drugs and steroids were administered.

In the 8th day of hospitalization (on the June 28) the Ceasarian section (ICD20: 82.0), from transverse cut was performed, at 35th week of pregnancy. The patient gave birth to a live daughter with Apgar 10/10. The girl's weigh was $2510 \mathrm{~g}$ and her body's length was $53 \mathrm{~cm}$. The course of hospitalization was uncomplicated and patient was discharged from the Mother and Child Health Center in Zabrze on the July 3.

\section{DISCUSSION}

Contrary to popular opinion, diagnosis of uterine fibroids during pregnancy is not an easy issue. In physical examination, it is possible to diagnose $42 \%$ of large $(>5 \mathrm{~cm})$ and $12.5 \%$ of smaller fibroids $(3-5 \mathrm{~cm})$ [8]. The usefulness of ultrasound examination in pregnancy is limited, mainly due to the difficulty in differentiating the physiological thickening of the uterine myometrium. During USG examination fibroids are only diagnosed in $1.4-2.7 \%$ of cases [9].
It may seem that conservative treatment, before pregnancy, is a much safer method of treatment of uterine fibroids, however it has been reported that prenatal myomectomy can be safely performed in the first and second trimester of pregnancy [10], and perinatological results in women subjected to this operation are comparable to those obtained in women treated conservatively [11].

Various studies reported a lower incidence of premature labor, premature rupture of membranes and preterm labor in a group of women who underwent elective myomectomy during pregnancy than in a group who received conservative treatment and a control group of pregnant women with no evidence of leiomyomas. The authors concluded that elective myomectomy during pregnancy as a preventative measure before the onset of acute complications is a safe option when done early in carefully selected patients [12].

The pregnancy of our patient was extremely high-risk with placental abruption. We confirmed following risk factors: submucosal myomas, placental implantation in direct contact with uterine myoma and the myoma with volume greater than $500 \mathrm{~cm}^{3}$. Myomas with size of $25 \mathrm{~cm}$ could also lead to abnormal fetal position, and subsequentaly to perinatal complications.

We need to remember that myomas can distort the architecture of the uterus and interfere with myometrial contraction, leading to uterine atony and postpartum bleeding. Also one of the studies showed that retained placenta is more common in all women with myomas compared to the control group, regardless of the location of the fibroid ( $1.4 \%$ and $0.6 \%$, respectively) [8].

The patient met the criteria, qualifying her for the procedure, i.e. lack of response to conservative treatment, severe pain due to degeneration of the submucosal or pedunculated myoma, fast growing myoma and large myoma $(>5 \mathrm{~cm})$ located in the lower part of the uterus [12].

The decision to carry out myomectomy in 19th week of pregnancy allowed to avoid the above risks, and allowed fetus to develop.

It is recommended to perform Caesarean section on women who underwent myomectomy during pregnancy, due to fear of intrauterine rupture of the uterus. This method of terminating pregnancy was decided in the case of our patient [11].

There are other therapeutic options for uterine myomas. If they do not threaten the development of pregnancy in a direct way, however, they make it difficult to deliver or may result in post-partum hysterectomy, it is possible to perform myomecotmy during caesarean section. Nowadays, it is believed that every effort should be made to avoid caesarean section, taking myomectomy case into consideration, due to a reasonable risk of severe haemorrhage requiring blood transfusion, uterine artery ligation and / or intra- and post-operative hysterectomy [13-15]. 
Pedunculated myomas can be safely removed during caesarean section without increasing the risk of hemorrhage [16].

Bilateral uterine arterial embolization (UAE) is a method, that allows to control postpartum bleeding. UAE application immediately after cesarean section in women with uterine myomas can effectively reduce postpartum blood loss and minimize the risk of myomectomy or hysterectomy. but it is absolutely contraindicated in pregnant women and in women planning pregnancy in the future [17].

\section{CONCLUSIONS}

Uterine fibroids are one of the most common benign tumors of the female genital tract. The major complication of myomas in pregnancy is recurrent pain. It can usually be controlled by conservative treatment, however, in rare cases, fibroids may require surgical resection, as in our patient's case [18].

In the majority cases of women with fibroids, pregnancy goes ahead without complications, however, according to literature data, in these cases were observed: increased frequency of spontaneous abortions and premature births, increased risk of bearing ablation, higher incidence of maternal-fetal incommunicability, incorrect position of the fetus, more often performed cesarean surgery, higher probability of postpartum haemorrhage. Prenatal myomectomy can be safely performed in the first and second trimester of pregnancy, however it is recommended to deliver the baby via Caesarean section, due to fear of intrauterine rupture of the uterus.

UAE is an alternative procedure for surgical intervention in the treatment of symptomatic uterine myomas, but it is absolutely contraindicated in pregnant women and in women planning pregnancy in the future

\section{Conflict of interests}

The authors declare no conflict of interest.

\section{REFERENCES}

1. Casini ML, Rossi F, Agostini R, et al. Effects of the position of fibroids on fertility. Gynecol Endocrinol. 2006; 22(2): 106-109, doi: 10.1080/09513590600604673, indexed in Pubmed: 16603437.
2. Klatsky PC, Tran ND, Caughey AB, et al. Fibroids and reproductive outcomes: a systematic literature review from conception to delivery. Am J Obstet Gynecol. 2008; 198(4):357-366, doi: 10.1016/j.ajog.2007.12.039, indexed in Pubmed: 18395031.

3. Neiger R, Sonek JD, Croom CS, et al. Pregnancy-related changes in the size of uterine leiomyomas. J Reprod Med. 2006; 51(9):671-674, indexed in Pubmed: 17039693.

4. Flake GP, Andersen J, Dixon D. Etiology and pathogenesis of uterine leiomyomas: a review. Environ Health Perspect. 2003; 111(8): 1037-1054 doi: 10.1289/ehp.5787, indexed in Pubmed: 12826476.

5. Coronado GD, Marshall LM, Schwartz SM. Complications in pregnancy, labor, and delivery with uterine leiomyomas: a population-based study. Obstet Gynecol. 2000; 95(5): 764-769, indexed in Pubmed: 10775744.

6. Egbe TO, Badjang TG, Tchounzou R, et al. Uterine fibroids in pregnancy: prevalence, clinical presentation, associated factors and outcomes at the Limbe and Buea Regional Hospitals, Cameroon: a cross-sectional study. BMC Res Notes. 2018; 11(1): 889, doi: 10.1186/s13104-018-4007-0, indexed in Pubmed: 30545402.

7. Vlahos NF, Theodoridis TD, Partsinevelos GA. Myomas and Adenomyosis: Impact on Reproductive Outcome. Biomed Res Int. 2017; 2017: 5926470, doi: 10.1155/2017/5926470, indexed in Pubmed: 29234680.

8. Awoleke JO. Myomectomy during Caesarean Birth in Fibroid-Endemic, Low-Resource Settings. Obstet Gynecol Int. 2013; 2013: 520834, doi: 10.1155/2013/520834, indexed in Pubmed: 24348568.

9. Lee HJ, Norwitz ER, Shaw J. Contemporary management of fibroids in pregnancy. Rev Obstet Gynecol. 2010; 3(1): 20-27, indexed in Pubmed: 20508779.

10. Rosati $P$, Exacoustòs $C$, Mancuso $S$. Longitudinal evaluation of uterine myoma growth during pregnancy. A sonographic study. J Ultrasound Med. 1992; 11(10): 511-515, indexed in Pubmed: 1404579.

11. Celik C, Acar A, Ciçek N, et al. Can myomectomy be performed during pregnancy? Gynecol Obstet Invest. 2002; 53(2): 79-83, doi: 10.1159/000052997, indexed in Pubmed: 11961378.

12. De Carolis S, Fatigante G, Ferrazzani S, et al. Uterine myomectomy in pregnant women. Fetal Diagn Ther. 2001; 16(2): 116-119, doi: 10.1159/000053893, indexed in Pubmed: 11173960.

13. Rothmund R, Taran FA, Boeer B, et al. Surgical and Conservative Management of Symptomatic Leiomyomas during Pregnancy: a Retrospective Pilot Study. Geburtshilfe Frauenheilkd. 2013; 73(4): 330-334, doi: 10.1055/s-0032-1328437, indexed in Pubmed: 24771919.

14. Kumar RR, Patil M, Sa S. The utility of caesarean myomectomy as a safe procedure: a retrospective analysis of 21 cases with review of literature. J Clin Diagn Res. 2014; 8(9): OC05-OC08, doi: 10.7860/JCDR/2014/8630.4795, indexed in Pubmed: 25386485.

15. Brown D, Fletcher HM, Myrie MO, et al. Caesarean myomectomy--a safe procedure. A retrospective case controlled study. J Obstet Gynaecol. 1999; 19(2): 139-141, doi: 10.1080/01443619965435, indexed in Pubmed: 15512253.

16. Kwawukume EY. Caesarean myomectomy. Afr J Reprod Health. 2002; 6(3): 38-43, indexed in Pubmed: 12685407.

17. Dao D, Kang SJ, Midia M. The utility of apparent diffusion coefficients for predicting treatment response to uterine arterial embolization for uterine leiomyomas: a systematic review and meta-analysis. Diagn Interv Radiol. 2019; 25(2):157-165, doi: 10.5152/dir.2019.18294, indexed in Pubmed: 30774092

18. Pron G, Mocarski E, Bennett J, et al. Ontario UFE Collaborative Group. Pregnancy after uterine artery embolization for leiomyomata: the Ontario multicenter trial. Obstet Gynecol. 2005; 105(1): 67-76, doi: 10.1097/01. AOG.0000149156.07061.1f, indexed in Pubmed: 15625144. 